\title{
Tocar:
}

\section{atenção ao vínculo no ambiente hospitalar}

Maria Martha Duque de Moura ${ }^{1}$ Maria Beatriz Lisbôa Guimarães ${ }^{2}$

Madel Luz $^{3}$

MOURA, M. M. D.; GUIMARÃES, M. B. L.; LUZ, M. Touch: attention to the bounds in the hospital setting. Interface (Botucatu), v.17, n.45, p.393-404, abr./jun. 2013.

The links between patients and health professionals in a public hospital specialized in high cliff fetal pregnancy and high complexity diseases were investigated, aiming to found the actions that could positively contribute to the therapeutic process in the mental health field, concerning the links between patients and health professionals that include professional and affective care, warm atmosphere and communication spaces the hospital setting. The research used qualitative methodology (participant observation and speech analysis), focusing the attendance routines in this maternity. The investigation subjects were mothers, families and professionals. Results indicate the importance of the attention and the link between health professionals and pregnant women, and could contribute to the construction of a possible link between parents and babies in adverse situations.

Keywords: Bound. Therapeutic touch. Physician-patient relation. Perinatal care.
Foram investigados vínculos entre profissionais de saúde e pacientes em hospital materno-infantil terciário e público, especializado em gravidez de alto risco fetal e doenças de alta complexidade na infância e adolescência, visando verificar se intervenções que "tocam" (mães/bebês) poderiam minimizar o estresse do ambiente hospitalar e interferir positivamente no processo terapêutico. Referimo-nos às ações que contribuem para os vínculos entre profissional de saúde, paciente e bebê, que incluem cuidado profissional técnico e afetivo, conforto ambiental, espaços para expressão dos sentimentos e comunicação. A pesquisa, de natureza empírico-operativa, utilizou metodologia qualitativa (observação participante e análise de discurso), tendo como sujeitos mães, familiares e profissionais. Resultados indicam a importância do acolhimento e vínculo entre profissionais de saúde e gestantes que vivem gravidez de alto risco fetal no ambiente hospitalar investigado, podendo favorecer a construção do vínculo possível entre pais e bebês em situações adversas.

Palavras-chave: Vínculo. Toque terapêutico. Relação médico-paciente. Cuidado perinatal.

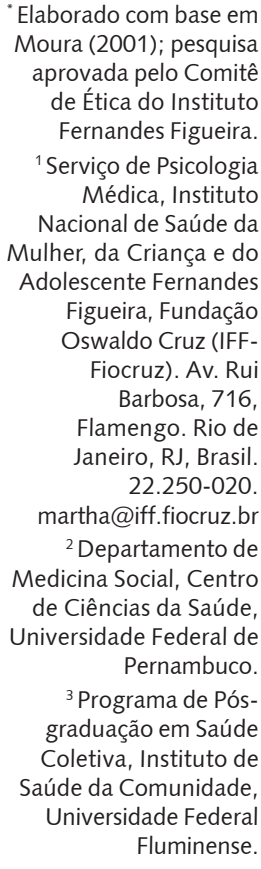

Elaborado com base em Moura (2001); pesquis aprovada pelo Comitê de Ética do Instituto Fernandes Figueira.

${ }^{1}$ Serviço de Psicologia Médica, Instituto Nacional de Saúde da Mulher, da Criança e do Adolescente Fernandes Figueira, Fundação Figueira, Fundação ruz (IFFFiocruz). Av. Rui Barbosa, 716, Flamengo. Rio de Janeiro, RJ, Brasil. 22.250-020 martha@iff.fiocruz.br ${ }^{2}$ Departamento de Medicina Social, Centro de Ciências da Saúde Universidade Federal de Pernambuco ${ }^{3}$ Programa de Pósgraduação em Saúde Coletiva, Instituto de Saúde da Comunidade, Universidade Federal Fluminense. 


\section{Introdução}

O cenário da pesquisa é a maternidade do Instituto Nacional de Saúde da Mulher, da Criança e do Adolescente Fernandes Figueira (IFF) - unidade materno-infantil terciária da Fundação Oswaldo Cruz (Fiocruz)/Ministério da Saúde, sendo os sujeitos as mães (grávidas e puérperas, antes e após o nascimento de seus filhos), seus familiares (sobretudo pais e avós) e os profissionais que trabalham na maternidade.

Num hospital materno-infantil público como este, lidamos com gravidez de alto-risco para o feto, e com crianças que, frequentemente, necessitam de longas e repetidas internações em Unidades de Tratamento Intensivo ou em enfermarias. Tais crianças convivem com malformações, doenças crônicas, graves, muitas vezes incuráveis, e serão, em muitos casos, dependentes de tecnologia para sobreviver. Tarefa difícil para a família, sobretudo a mãe, mas, também, para sua rede social, bem como para nós, profissionais de saúde, que convivemos diariamente com esta realidade.

Os profissionais deste Instituto convivem diariamente com mulheres e suas famílias em momento de grande sofrimento. Gerar um bebê com alto risco de vida (gravidezes de alto risco fetal), muitas vezes incompatível com a vida extrauterina, é missão quase impossível.

Essas crianças são cotidianamente submetidas, no hospital, ao contato físico doloroso durante procedimentos que, eventualmente, são mutilantes. Trata-se de um cuidado que dói. Sua forma corporal pode ser alterada por cirurgias, procedimentos ou pela própria doença, antes mesmo que possa construir uma imagem corporal própria.

Em situação de risco pela doença e pelo afastamento de sua família, essas crianças são, muitas vezes, pouco investidas afetivamente. É mais fácil gostar, se vincular e acariciar uma criança bonita, não prematura, perfeita e desejada. É difícil o estabelecimento de vínculo mãe-filho quando a criança é "feia", malformada ou deformada, muito pequena, doente, vivenciando internações repetidas ou prolongadas. Trata-se da distância entre o bebê ideal e o bebê real (Klaus, 1993). Estas crianças não são muito tocadas corporalmente (afeto) e são muito manipuladas por procedimentos invasivos (punções para coleta de exames, por exemplo).

Pensamos que o sentido do "afeto" no toque já deve ser esclarecido: as crianças são muito tocadas, sim, mas no sentido contrário ao do afeto, ou seja, manipuladas tecnicamente. O toque com finalidade de acolhimento do bebê estabelece uma comunicação, e o toque "profissional" ou técnico pode estabelecer uma "distância" entre o pequeno ser e o mundo humano, justamente pelo contraste entre a vida intrauterina cálida e esta "exterior" e "fria".

O termo "tocar" se define, neste trabalho, enquanto contato físico - o tocar com as mãos -, mas, também, o "tocar" que envolve o outro, a atenção com a ambiência (visual, sonora, vocalizações, luminosidade etc.) que afeta a qualidade da relação e contribui para o vínculo, para os encontros que se estabelecem no processo terapêutico (Brasil, 2010a).

Algumas questões estiveram presentes ao longo de todo o trabalho e os resultados apontam para o desdobramento delas: o toque assegurador, o olho no olho, o diálogo, o conforto ambiental poderiam minimizar o estresse das diversas intervenções médicas no cotidiano do ambiente hospitalar? Nossos profissionais de saúde estão suficientemente sensibilizados para a importância da atenção ao vínculo no seu trabalho cotidiano? É possível resgatar o toque bom, afetivo, mesmo em situações tão adversas? Cabe prescrever colo em nossas evoluções médicas? Em síntese: O sistema terapêutico pode ter mais eficácia se "tocar"?

Ressaltamos o papel fundamental do cuidador no processo terapêutico do paciente internado, na medida em que os cuidados do dia a dia, oferecidos tanto pelos familiares quanto pelos profissionais de saúde, constituem preciosos momentos para proporcionar conforto, acolhimento e fortalecimento do vínculo entre a criança, os pais e os profissionais de saúde (Winnicott, 1978). O objetivo do presente artigo é apresentar alguns resultados da pesquisa que procurou investigar acerca do vínculo assegurador no ambiente hospitalar para a qualidade de vida do bebê e de suas famílias. 
O estudo se insere na linha de pesquisa "Análise de recursos terapêuticos a partir da doença crônica", coordenada pela primeira autora, e está registrada no Departamento de Pesquisa do Instituto Nacional de Saúde da Mulher, da Criança e do Adolescente Fernandes Figueira, tendo sido aprovada pelo comitê de ética da instituição.

\section{Metodologia}

Esta pesquisa se apoia na experiência clínica da primeira autora, ao longo de doze anos, no serviço de psicologia médica na assistência perinatal. Esse Instituto recebe gestantes encaminhadas de diferentes unidades de saúde do município do Rio de Janeiro, de fora dele, e, até mesmo, de outros estados. A assistência oferecida pela Psicologia Médica deste hospital é constituída pelas seguintes atividades: a) atendimento individual de grávidas acompanhadas no IFF por demanda própria ou de profissionais do pré-natal, b) grupo operativo semanal na enfermaria de gestantes internadas, c) atendimento psicoterápico focal individual a partir da triagem no grupo - fruto da demanda da própria paciente ou de algum profissional, d) oficina semanal de arteterapia, também na enfermaria de gestantes, e e) assistência de psicologia no alojamento conjunto, onde as mães ficam com os seus bebês. Durante a pesquisa, oferecemos, semanalmente, música de ninar nas enfermarias.

No cotidiano de seu trabalho na maternidade, a psicologia médica realiza, ainda, atividades de interconsulta com os demais profissionais de saúde e participa de sessões clínicas semanais de perinatologia (clube do feto). Algumas dessas mulheres são ainda acompanhadas ambulatorialmente após a alta.

A presente pesquisa visa aprimorar a assistência dessas pacientes, uma vez que a internação constitui um momento traumático para a gestante e sua família, acrescido do sentimento de abandono, pois estas pacientes ficam longe de suas referências, e a visitação nem sempre é frequente, devido a dificuldades financeiras e pouca disponibilidade de tempo dos familiares (muitas pacientes moram longe, em outros municípios).

A coleta de dados da pesquisa se deu a partir da observação decorrente da prática clínica da primeira autora, tanto como coordenadora de grupos operativos com gestantes quanto por meio de contatos informais com os profissionais da maternidade. Foram realizadas anotações em diário de campo e registro de depoimentos. O presente artigo tem como foco a análise dos grupos operativos e os atendimentos individuais focais, no período de agosto de 2005 a fevereiro de 2009 . Foram analisados 62 grupos operativos com 493 participantes, sendo 454 pacientes internadas na enfermaria de gestantes e 39 acompanhantes, sobretudo pais e avós.

O grupo operativo consiste em reunião focando tarefas específicas, no caso, como lidar com uma gravidez de alto risco fetal ou a internação hospitalar, por exemplo (Rivière, 1988). Esse grupo é coordenado pela primeira autora e realizado semanalmente com as gestantes internadas na enfermariae os familiares que as estiverem acompanhando no momento. Considera-se sempre oportuna a participação de algum membro da equipe de saúde da enfermaria. Além da triagem de pacientes para atendimento individual, esse grupo pretende contribuir para o maior acesso das pacientes à informação, para o acolhimento das questões emocionais, bem como para o estímulo e valorização do suporte mútuo (Moura, Carneiro, 2010).

Neste estudo empregou-se metodologia qualitativa, com emprego de observação participante e análise dos dados apoiada nas pesquisas desenvolvidas por Spink (1999). Com base em uma perspectiva construcionista, buscou-se analisar a produção de sentidos a partir de práticas discursivas dos sujeitos da pesquisa, por meio do levantamento e seleção de temas recorrentes expressos (Spink, 1999).

Consideramos como sujeitos da pesquisa: o Sistema Terapêutico, constituído pela criança, sua família (gestante, puérpera e, sobretudo, o pai ) e profissionais de saúde das enfermarias de gestantes e alojamento conjunto do IFF. 
Além de uma tomada dos temas recorrentes nos grupos, analisamos a trajetória de uma gestante que foi acompanhada em psicoterapia durante dois anos, pois esteve internada com gravidez de feto tido como inviável, teve sua filha que permaneceu internada neste hospital ao longo dos seis meses de sua vida.

\section{Contextualização teórica}

O vínculo mãe-bebê e sua importância para o desenvolvimento afetivo do ser humano é objeto de pesquisa, sobretudo, a partir dos anos 1950. Bowlby (1984), psiquiatra inglês, apoiado em método observacional etológico, apresenta a hipótese de que a necessidade de apego é, também, primária (ou seja, não derivada de nenhuma outra), e fundamental para o desenvolvimento da personalidade. No final da década de 1960, os relatórios de Mary Ainsworth sobre suas observações em Uganda e seu Baltimore Longitudinal Study estabelecem o caminho dos estudos sobre o apego na tradição BowlbyAinsworth para algumas gerações de pesquisadores (Grossmann, Grossmann, Waters, 2008).

Para Bowlby (1984), o bebê nasce com uma vasta gama de potencial de ação pronta para ser ativada (sucção, acompanhamento ocular, preensão, choro, dito de outra forma, os reflexos arcaicos), e que tais ações se endereçam progressivamente a uma figura cada vez mais discriminada, que, na nossa sociedade, é representada pela figura da mãe, uma vez que é ela quem, frequentemente, assume os cuidados do bebê. À medida que a criança cresce, sua gama de comportamentos de apego se enriquecem: sorriso, chamado, tentativa de contato, locomoção, que têm como meta a procura de proximidade com a figura de apego.

A pulsão de apego se opera entre os homens pela busca de um contato - no duplo sentido corporal e social do termo - que garante uma dupla proteção contra os perigos exteriores e o estado psíquico interno de desamparo. Ela torna possível as mudanças de sinais em uma comunicação recíproca, onde cada parceiro se sente reconhecido pelo outro (Bowlby,1984).

Para que o papel de socialização seja positivo, é necessário que a criança tenha a certeza de retomar o contato com sua mãe se ela desejar e no momento em que desejar; ela se torna, então, capaz de explorar seu ambiente (lugares estranhos e pessoas desconhecidas). Os estudos exploram, então, os efeitos da privação da figura de apego para o desenvolvimento afetivo do ser humano (Bowlby, 2006).

Winnicott, em 1956, descreveu a preocupação materna primária - um estado que sensibiliza a mãe ao longo da gravidez - para perceber as necessidades do seu bebê. A competência do bebê como interlocutor ativo neste diálogo é, a cada dia, mais documentada e ressaltada (Golse, 2008; Brazelton, 1982; Stern, 1981).

Os trabalhos de Montagu (1971) e Didier Anzieu (1989) evidenciam a influência precoce e prolongada das estimulações táteis sobre o funcionamento e desenvolvimento do indivíduo. A busca do contato corporal entre mãe e bebê é um fator essencial para o desenvolvimento afetivo, cognitivo e social deste último.

A pele é o primeiro instrumento e lugar de troca com o outro. Ela ocupa uma superfície muito maior do que qualquer outro órgão dos sentidos e aparece no embrião antes dos outros sistemas sensoriais (em torno do segundo mês de gestação), comportando uma grande densidade de receptores (Anzieu, 1989). Anzieu fala deste "envelope" tátil, mas, também, do sonoro, olfativo e visual.

Na teoria de Winnicott (1978), a integração do Eu no tempo e espaço depende da maneira da mãe "segurar" (holding e handling) o recém-nascido. Este conceito foi ampliado para círculo maternante (Anzieu, 1989) e envelope de maternagem (Brazelton, 1988), o que nos permite pensar na importância de todos os demais contatos estabelecidos com a criança. O círculo materno é assim chamado porque ele "circunda" o bebê com um envelope externo feito de mensagens (Anzieu,1989).

Frédérick Leboyer, obstetra francês, em seu livro "Shantala, A Arte Tradicional Indiana de Massagens para Bebês" (1976), fotografou a sequência de uma técnica milenar empregada por uma jovem mãe indiana paralítica que massageava seu filho em uma rua. Neste caso, a massagem se torna uma mensagem. 
Utilizamos, neste trabalho, o termo bebê nos referindo tanto ao feto como ao recém-nascido. Nossa escolha pelo termo bebê foi intencional no sentido de ressaltar a subjetividade, a afetividade. A observação de bebês ainda no útero se tornou possível com as tecnologias, sobretudo a ultrassonografia, ampliando nossa atenção para a vida afetiva fetal (Canault, 2001).

Nesta perspectiva, a "conversa" com o bebê ainda em útero amplia e confirma o vínculo entre pais e filhos, a parentalidade. Evocamos os conhecimentos da haptonomia, criada por Frans Veldman (1989) após a segunda guerra mundial. O termo haptonomia vem do grego clássico "hapsis" e "hapteme", que designam o tato, o sentido e o sentimento. A haptonomia se define como uma ciência humana empírica que acredita que o tocar pode confirmar afetivamente o outro dentro de sua existência para estabelecer um estado de segurança de base. A haptonomia perinatal se desenvolveu muito nos últimos vinte anos na França.

No hospital, os cuidados das gestantes, do recém-nascido ou de crianças que necessitam uma maior permanência nesta instituição acontecem no banho, na troca de roupas, na arrumação da cama destes pacientes, no momento das refeições, durante o exame físico ou nos procedimentos invasivos realizados pelos profissionais de saúde. Os diferentes momentos, se valorizados devidamente, podem significar oportunidades de contato assegurador, fazendo uma enorme diferença para os pacientes (Brasil, 2011).

A maneira como os cuidadores - pais, familiares ou profissionais de saúde - seguram o corpo da criança, como a carregam, a segurança que passam quando a sustentam são essenciais. O contato epidérmico pode ser total e terno, os cuidados rotineiros podem ser executados com ou sem calor afetivo, podem ou não trazer conforto e acolhimento. Entendemos que os cuidados podem ser técnicos e afetivos. O bebê recebe os gestos deste círculo maternante como uma estimulação, mas, também, como uma comunicação.

Da perspectiva do profissional de saúde, em termos mais amplos, podemos constatar que a Medicina Ocidental Contemporânea, fundamentada na física clássica, estruturou-se com base no pensamento racional e nos procedimentos técnicos (Luz, 2004), buscando um elevado grau de determinação e objetividade. Deixou de lado, em contrapartida, a arte de curar, que implica criatividade, pois exige do terapeuta mais do que assimilação de conhecimento, exige sensibilidade e intuição para lidar com o novo, o contingente e o desconhecido (Guimarães, 2005).

Lilia Schraiber refere-se ao trabalho médico moderno como uma "estrutura instável", uma vez que a prática clínica possui um lado técnico, auxiliada pelo desenvolvimento das ciências e das tecnologias, mas possui, também, outra dimensão que recai, segundo a autora, "na singularização do ato, nas especificidades de cada intervenção em particular, para o que é preciso uma técnica mais criativa, em que seu agente seja capaz de inovar" (Schraiber, 1997, p.175).

Nessa instância, a prática clínica aproxima-se da arte, pois requer do profissional de saúde uma sensibilidade às especificidades de cada situação, sendo a intervenção fruto e origem da experiência individual, e duplamente particularizada, pois incide sobre cada indivíduo, a cada encontro.

Nesse sentido, ressaltamos a importância e a singularidade do encontro terapêutico, que se constitui não somente enquanto aspectos técnicos, mas é permeado por afetos, que, segundo Espinosa (1973), não têm o sentido de emoções, mas simplesmente daquilo que afeta, atinge, modifica, aumentando ou diminuindo a potência do indivíduo. Pois, para esse autor, nossos corpos são constituídos por relações internas entre os órgãos, por relações externas com outros corpos e por afecções, isto é, pela capacidade de afetar outros corpos e ser por eles afetado sem se destruir.

"Deixar-se afetar" é parte importante do encontro terapêutico e da construção conjunta de um processo terapêutico, e isto implica uma disponibilidade para o encontro por parte do profissional de saúde, um deixar-se fluir junto ao tempo, ao "aqui e agora". Tom Andersen (2002) define a intuição como um estado de se estar aberto às respostas que vêm de "dentro" quando se é tocado pelo que vem de "fora". O autor pontua que os toques que vêm 'de fora' chegam até os olhos, ouvidos e pele. "Se estou aberto e recolho esses toques, terei 'respostas' 'dentro' de mim que me dirão como reagir aos toques" (2002, p.151).

Para o filósofo francês Henri Bergson (1974), a intuição se dá a partir dos sentidos e da sensibilidade, que se expressam quando o sujeito está aberto e em sintonia com o momento presente, pulsando junto 
com o outro e com tudo aquilo que os circunda. Além disso, o autor assinala que é necessário que haja também uma percepção de si mesmo, ou seja, uma percepção duplicada, onde o sujeito se vê a partir da situação presente, de forma que todos os seus sentidos estejam presentes naquele momento.

A singularidade do Método Intuitivo, proposto por Bergson, recai, sobretudo, em uma atitude de despojamento diante das ideias preconcebidas e, portanto, fixas e imutáveis, em função de um deixarse fluir, junto ao tempo, para que, a partir dessa vivência harmônica na 'duração', possam emergir os signos e sinais capazes de dar as chaves para a compreensão do sofrimento do outro. A partir dessa vivência compartilhada, permeada por afetos, sensações, ideias e percepções sensíveis, o profissional de saúde torna-se mais apto a intuir, através de sua sensibilidade, aquilo que pode estar afligindo o seu paciente. A intuição apresenta-se sempre como uma totalidade, sob a forma de síntese, mas, logo em seguida, vem o pensamento racional para elaborar, comparar e analisar aquilo que foi intuído, recorrendo ao conhecimento que o profissional já possuía anteriormente. Bergson pretende, com este método, substituir os conceitos eternos pela contínua novidade, através da ideia de criação; almeja alcançar isto com a participação consciente dos sujeitos nesta criação (Guimarães, 2005).

\title{
Discussão
}

\section{Ambiência}

O período perinatal implica um processo de mudança para as famílias. Aqui, parto, partir, deixar partir, se despedir do bebê ideal e fazer vínculo com o bebê real também não é simples. É admirável a criatividade, a coragem dessas famílias ao enfrentarem as dificuldades de cada momento. É traumática para os pais a vivência de uma gravidez de alto risco fetal. O fato de gerar uma criança malformada representa um golpe importante para a qualidade do vínculo pais-bebê.

Observamos ambivalência, especialmente intensa, nestas situações, narradas nos depoimentos:

\begin{abstract}
"Eu não sei se vou conseguir ser uma boa mãe para esta criança, não sei se vou conseguir cuidar dele". "Eu estou aqui internada faz muito tempo, mas quando eu desanimo, eu penso nele, no quanto ele precisa de mim". "O pai, assim que soube dos problemas com nosso bebê desapareceu". "Tem um ditado que diz que filho feio não tem pai". "Se eu pudesse, eu (grávida internada) também sumia, deixava a barriga aqui no hospital e ia dar uma volta para arejar, descansar do assunto... mas não dá, né?"
\end{abstract}

Muitos homens, ao saberem dos problemas com o bebê, não suportam a intensidade dos sentimentos e se separam destas mães que, quando podem, recorrem às suas famílias de origem. Mais uma razão para que o ambiente neste hospital seja especialmente acolhedor e protetor do binômio mãe-filho.

Também é ambivalente o sentimento do profissional que lida cotidianamente com essa realidade. Em muitos momentos, ele se pergunta se deve ou não investir naquela gravidez, naquele bebê. Suportar essas ambivalências é tarefa difícil para todo o sistema terapêutico.

É traumático para estas grávidas, fragilizadas pela gravidez de alto risco, permanecerem internadas, longe de suas referências familiares, ambientais e sociais. Queixam-se da falta de acompanhante durante a internação ou da restrição de horários de visitas: "Ficar longe do meu marido, da minha casa, do meu banheiro e até dos meus problemas é muito difícil"; "Moramos muito longe, meu marido trabalha, só pode vir me visitar fora do horário de visitas, isso quando pode me visitar porque gasta muito tempo e dinheiro de passagem para vir aqui".

Vale a pena ressaltar como o telefone celular contribuiu para a comunicação dessas pacientes com seus familiares nos últimos dez anos. Hoje, a maioria tem um celular para se comunicar nas emergências (clínicas e emocionais). Antes dispunham de um telefone público no andar da maternidade ou os familiares podiam ligar para a maternidade para falar com os profissionais e ter notícias. 
O ambiente hospitalar muitas vezes intensifica o isolamento social dessas pacientes: “Daqui não sei se é dia ou noite porque as luzes ficam acesas direto, se o tempo tá bom ou vai chover não dá prá ver, nem sei direito que dia é hoje, aqui a gente perde a noção do tempo". Os ruídos no hospital também contribuem para o isolamento - alarmes de equipamentos que disparam todo o tempo, o choro ou o grito de outras pacientes -, assim como o cheiro da UTI.

O trabalho realizado no IFF segue alguns conceitos preconizados pela Política Nacional de Humanização (PNH) vigente no Ministério da Saúde. Um desses conceitos refere-se à "ambiência" do espaço hospitalar, que diz respeito a três eixos fundamentais: em sentido físico, em relação ao potencial de possibilitar a produção de subjetividades, e como ferramenta facilitadora do processo de trabalho (Brasil, 2006).

A ambiência física nos espaços do IFF valoriza elementos do ambiente que interagem de forma positiva, na medida do possível, com as pessoas, tais como: som ambiente com músicas de ninar, cor e enfeites (desenhos, dobraduras etc.) utilizados como decoração nas paredes, iluminação, cheiro etc. -, de forma a propiciar conforto e acolhimento.

Profissionais e pacientes referem bastante satisfação quando, nas sextas-feiras, oferecemos música ambiente (cantigas de ninar brasileiras) no alojamento conjunto: "Me lembrei da minha infância", "meu filho que estava chorando, acabou dormindo", "hoje vocês demoraram a chegar". Tais músicas os conectam com suas próprias infâncias, suas histórias familiares de cuidados de crianças.

Percebemos que a maternidade em geral é um ambiente essencialmente feminino, frequentado pelas mães e cuidadoras, na sua maioria mulheres. Atualmente, procuramos incentivar a frequência do pai nos cuidados da criança desde o evento gravidez, parto e puerpério. A presença do pai no acompanhamento da gravidez, no parto e nos cuidados das crianças fortalece seu vínculo afetivo com a criança e sua família. Culturalmente, percebemos o homem, o pai, como aquele que envolve e protege o binômio mãe-filho. Muitas vezes, utilizamos músicas de ninar cantadas por homem com o intuito de valorizar sua presença.

Quanto ao potencial de possibilitar a produção de subjetividades, as gestantes estão especialmente sensíveis à qualidade dos vínculos no ambiente hospitalar devido à gravidez, ao alto risco fetal e ao afastamento de seu apoio social habitual. Elas elegem naturalmente alguns profissionais para buscarem apoio emocional e, mesmo, informações durante a internação; percebem, à sua maneira, a qualidade do vínculo: "não tem jeito, o meu santo cruza com algumas pessoas aqui, com outras não". Por outro lado, diversas vezes, os profissionais buscam apoio da psicologia se queixando que aquela paciente está com implicância com eles e que questiona sua competência técnica. Trata-se, muitas vezes, de um mecanismo de defesa denominado projeção, em que a paciente projeta, nos profissionais, o seu sentimento de incompetência, a culpa pela situação ora vivida.

Alguns profissionais reconhecem que, por excesso de trabalho ou questões pessoais, por vezes, executam suas atividades de forma mecânica ("estava no automático"). Entretanto, já podemos considerar um avanço nas relações da equipe multiprofissional o fato de esses profissionais terem esta percepção. Talvez alguns estejam sendo estimulados a refletir sobre suas ações a partir da sua participação nos grupos ou nos contatos com profissionais da psicologia. Muitos ainda não percebem o excesso de estímulos visuais e sonoros, outros desconhecem os protocolos para lidar com a dor nos recém-nascidos.

As gestantes se queixam muito da forma com que as más notícias são dadas pelos profissionais. Os termos técnicos, a frieza do profissional, sua distância, a falta de preparo para acolher o paciente nessa hora são recorrentes: "O médico foi falando logo que o meu bebê tinha problema, não tinha jeito, não ia sobreviver. Eu tava sozinha, fiquei duas horas no ponto de ônibus sem conseguir sair dali".

Com relação às questões abordadas acima, um importante instrumento que pode auxiliar no processo de trabalho é o protocolo SPIKES (Brasil, 2010a), que, ao discutir a atenção ao vínculo nas situações de notícias difíceis, se refere ao S (setting), considerando que tais notícias não devem ser dadas no corredor, e que os celulares dos profissionais devem ser desligados, por exemplo. Que, inicialmente, $\mathbf{P}$ (perception), a percepção do paciente quanto a sua situação, deve ser escutada. Em seguida I (invitation), o paciente deve ser convidado a saber o que o profissional tem a lhe dizer. $\mathrm{O}$ 
conhecimento K (Knowledge) da má noticia é então fornecido ao paciente, seguido de $\mathbf{E}$ (empaty) empatia, para, então, se construir conjuntamente a S (strategy), ou seja, o projeto terapêutico.

A empatia, o colocar-se no lugar do outro, ajuda os profissionais a se aproximarem do paciente para atenderem suas necessidades. Porém cabe lembrar que, por vezes, o que é ruim ou bom para os profissionais, talvez não o seja para o paciente. Apesar de muitas vezes sensibilizados para a importância desse contato assegurador, nós profissionais necessitamos estar atentos às questões culturais e individuais do paciente (sobretudo a criança maior ou a mulher), que, por vezes, não nos autoriza a tocá-lo, não suporta este contato. Esta autorização pode ser verbalizada ou não, mas diz respeito ao foro íntimo de cada um.

Percebemos claramente a relatividade das vivências para cada ser humano ao analisar a trajetória de uma paciente que foi acompanhada em psicoterapia, durante dois anos. Durante a gravidez, essa paciente recebeu o diagnóstico de uma síndrome genética em seu feto, tido como incompatível com a vida extrauterina. Deu à luz uma menina que sobreviveu e permaneceu internada neste hospital durante os seis meses de sua vida.

Para essa mãe, sua gravidez e o acompanhamento dedicado e afetivo ao seu bebê foi a "grande obra" de sua vida. Durante os anos que se seguiram à morte da criança e, mesmo nos contatos posteriores de follow up, essa mulher se refere de forma orgulhosa à experiência vivida, como tendo sido preciosa, edificante e transformadora de sua personalidade. Talvez sua religiosidade (ela era espírita) tenha contribuído para sua visão positiva da experiência, que, para muitos de nós, seria insuportável.

Os grupos operativos realizados no hospital se apresentam como outra ferramenta que contribui para a melhoria do processo de trabalho. São realizados por meio de encontros entre os sujeitos e que possibilitam a expressão das subjetividades; são espaços que propiciam reflexões sobre os processos tanto afetivos quanto de trabalho - vivenciados pelas gestantes, mães, familiares e profissionais. $O$ grupo amplia o apoio social e contribui na construção de redes no ambiente hospitalar. Por fim, tais grupos se constituem em espaços que favorecem a otimização de recursos, o atendimento humanizado, acolhedor e resolutivo (Brasil, 2006).

As gestantes de alto risco internadas neste hospital, em geral, percebem, de forma positiva, a participação nesses grupos, devido à oportunidade de falarem de seus sentimentos ambivalentes em relação àquela gravidez, de seus medos e recursos internos para lidarem com a adversidade. Muitas vezes, quando chegamos para o grupo semanal, elas já estão sentadas em roda nos esperando.

\section{Acolhimento}

O "acolhimento" é outra diretriz preconizada pela $\mathrm{PNH}$, e que se constitui como um modo ou ferramenta de produção da saúde. Nessa concepção, parte-se do princípio de que a vida não se passa apenas em cada um dos sujeitos, mas, sobretudo, se passa entre os sujeitos, nos vínculos que são construídos por meio das relações interpessoais.

Pode-se dizer que o acolhimento se constitui numa tecnologia do encontro, que se insere no contexto de afetar e ser afetado mediante os encontros. Isto tem como consequências: o reconhecimento do usuário como sujeito e participante ativo no processo de produção da saúde; a valorização e a abertura para o encontro entre o profissional de saúde, o usuário e sua rede social; uma reorganização do atendimento em saúde a partir da problematização dos processos de trabalho, de modo a incluir toda a equipe multiprofissional; a elaboração de projetos terapêuticos junto aos usuários com base em suas demandas; a operacionalização de uma clínica ampliada que implica a abordagem do usuário para além da doença e suas queixas, bem como a construção de vínculo terapêutico para fortalecer e potencializar o processo de produção de saúde (Brasil, 2010b). Nesse sentido, podemos constatar que todas essas ferramentas de produção de saúde estão presentes no trabalho realizado nos grupos operativos e nos atendimentos individuais do IFF.

Muitos cuidadores (especialmente a mãe) percebem e valorizam as oportunidades de oferecer conforto à criança, a partir do que Anzieu chama de envelopes tátil, sonoro, olfativo e visual. Assim, se sentem valorizados e importantes no processo terapêutico da criança, e o vínculo é fortalecido. 
O tocar pode ser adaptado às especificidades da criança hospitalizada e doente. Como exemplo, nos referimos ao fato de que o bebê prematuro é extremamente excitável e, por vezes, recorremos à colocação das mãos sobre sua cabeça ou corpo, sem nenhum movimento. Neste ambiente é necessário programar as diversas intervenções junto ao bebê internado a fim de racionalizar as frequentes ações, muitas vezes invasivas, a que a criança hospitalizada é submetida no seu dia a dia, reavaliando cotidianamente o protocolo de dor vigente no hospital pediátrico (Moreira, Braga, Morsch, 2003).

Por vezes, envolvemos a criança doente com nossa voz, com outro conforto ambiental até que o contato físico seja possível. Apoiados ainda nos trabalhos de Anzieu, consideramos as vocalizações dos pais com o recém-nascido importante recurso na constituição, ampliação e, mesmo, recuperação do vínculo afetivo pais-bebê. As vocalizações pais-bebês, assim como as músicas de ninar, constituem tecnologia de baixo custo e grande impacto. Estes recursos representam a possibilidade de retomar ou preservar o compromisso dos pais com seus filhos, as funções parentais.

\section{Considerações finais: implicações para a prática e para a pesquisa}

A atenção aos vínculos interpessoais precoces na atenção integral à primeira infância (zero a seis anos) se faz necessária. Como exemplos de formulações teóricas e de articulações intersetoriais de políticas públicas neste sentido, podemos citar a estratégia "Brasileirinhas e Brasileirinhos Saudáveis" do Ministério da Saúde (Brasil, 2010b), e a pesquisa avaliativa de sua implantação (Mendes, 2012).

Essa estratégia preconiza o fortalecimento de vínculos, o investimento nas relações que favoreçam os laços entre a criança e seus cuidadores, assim como entre os distintos profissionais envolvidos nas práticas de gestão do cuidado. O foco está, portanto, nas dimensões relacionais entre a criança e seus cuidadores, proporcionando a constituição e o fortalecimento de vínculos entre os profissionais e destes com os usuários e a comunidade.

Na clínica ampliada, referida anteriormente e que se constitui em uma das estratégias de acolhimento da $\mathrm{PNH}$, os espaços concretos de diálogo, entre diferentes profissionais, em torno do atendimento prestado ao paciente - como as sessões clínicas - possibilitam uma assistência mais integral e efetiva.

A coconstrução (profissionais e pacientes) de práticas humanizadas e integralizadas de atendimento valoriza a autonomia do paciente e seu protagonismo na construção de um processo terapêutico singular (Gomes, Pinheiro, 2005).

No modelo de gestão compartilhada, o protagonismo das famílias na produção de cuidado de crianças de zero a seis anos é ampliado. Esse protagonismo se refere, também, ao profissional de saúde que, apesar de estar apoiado em protocolos - desejáveis e necessários -, deve ter autonomia de, no ato do cuidado, construir, junto ao paciente, seu desenho terapêutico.

Vale a pena lembrar que, muitas vezes, desenvolvemos nossa competência técnica e nos esquecemos da competência afetiva, necessária para o trabalho diário com pessoas que sofrem. Corremos, assim, o risco de construírmos uma relação mecânica, automática e não criativa com o nosso trabalho (Moura, 2001).

Num hospital, com a complexidade do Instituto Nacional de Saúde da Mulher, da Criança e do Adolescente Fernandes Figueira, a especial atenção ao vínculo pode contribuir de forma importante no fortalecimento da relação dos pais com seus filhos, ampliando as possibilidades do sistema terapêutico. A tarefa de lidar com as repercussões de vivências traumáticas para a criança e sua família pode, então, ser compartilhada. É assim que o investimento no sentido de ampliar os recursos de relacionamento dos profissionais de saúde e seus pacientes se faz necessário (Maldonado, Canella, 2003).

No esforço de "medir" o vínculo no período perinatal, ressaltamos as escalas de vínculo (de Crawly, 1981, e Taylor et al., 2005, por exemplo) que visam contribuir para a observação do vínculo mãe-bebê durante a gravidez e o pós-parto. Ainda que limitadas, tais escalas apontam para o diagnóstico relacional.

Hoje, a consciência da importância do pai amplia nosso olhar para a tríade pai-mãe-bebê. Variáveis como suporte social e resiliência atestam a complexidade da questão e aumentam as possibilidades de intervenção. 
Importantes estudos longitudinais sobre apego, na tradição Bowlby-Ainsworth, demonstram a importância do vínculo pais-bebê e suas repercussões para o futuro afetivo do ser humano e para a sua capacidade de estabelecer e preservar laços. Inúmeras escalas avaliam os vínculos entre pais e filhos na gravidez, na primeira infância, entre seis e dez anos, na adolescência e no jovem adulto. A influência do apego seguro ou inseguro na qualidade da exploração e na resposta diante de situações estranhas ou novas é ressaltada (Grossmann, Grossmann, Waters, 2008).

A psicopatologia do bebê em torno, sobretudo, dos transtornos alimentares, de sono, de choro ou cólicas do primeiro ano de vida evidencia disfunções nas primeiras interações (Alvarez, Golse, 2008; Mazet, Stoleru, 1990). Hoje, se fala em depressão do bebê e de sua repercussão na vida afetiva do ser humano (Braconnier, Golse, 2010).

A terapêutica aponta para intervenções precoces com abordagem relacional de atenção aos vínculos. O que se discute hoje é quão precoce essas intervenções podem ser. Entendemos que a parentalidade - o processo de tornar-se pai e mãe - começa com o desejo de ter a criança, se desenvolve durante a gravidez e continua após o nascimento da criança. As intervenções precoces e consultas terapêuticas visam qualificar esses pais, no sentido de compreendê-los e ajudá-los criando espaços de reflexão e expressão (Solis-Ponton, 2004).

Essa pesquisa ressaltou a especial importância do acolhimento e do vínculo entre profissionais de saúde e gestantes que vivem gravidezes de alto risco fetal. A atenção aos vínculos neste ambiente hospitalar pode favorecer a construção do vínculo possível entre pais e bebês em situações adversas. Trata-se de alta tecnologia de baixo custo com importantes repercussões para o desenvolvimento emocional destas crianças e de suas famílias.

\section{Colaboradores}

Maria Martha Duque de Moura responsabilizou-se pela pesquisa de campo, pela análise dos dados e pela redação do artigo. Maria Beatriz Lisbôa Guimarães colaborou na análise dos dados e na redação do artigo. Madel Luz colaborou na redação do manuscrito.

\section{Referências}

ALVAREZ, L.; GOLSE, B. La psychiatrie du bébé. Paris: Puf Ed., 2008.

ANDERSEN,T. Processos reflexivos. 2.ed. Rio de Janeiro: Instituto Noos, 2002.

ANZIEU, D. O eu-pele. São Paulo: Casa do Psicólogo, 1989.

BERGSON, H. Introdução à metafísica. São Paulo: Abril Cultural, 1974. (Os Pensadores).

BOWLBY, J. Cuidados maternos e saúde mental. 5.ed. São Paulo: Martins Fontes, 2006.

Apego e perda. São Paulo: Martins Fontes, 1984.

BRACONNIER, A.; GOLSE, B. Dépression su bébé, depression de I'adolescent. Toulouse: Ed. Érès, 2010.

BRASIL. Ministério da Saúde. Secretaria de Atenção à Saúde. Núcleo Técnico da Política Nacional de Humanização. Ambiência. 2.ed. Brasília: MS, 2006.

Ministério da Saúde. Instituto Nacional de Câncer. Comunicação de noticias difíceis: compartilhando desafios na atenção à saúde. Rio de Janeiro: Inca, 2010a. 
BRASIL. Ministério da Saúde. Secretaria de Atenção à Saúde. Departamento de Ações Programáticas e Estratégicas em Saúde. O futuro hoje: estratégia brasileirinhas e brasileirinhos saudáveis primeiros passos para o desenvolvimento nacional. Brasilia: MS, 2010b. (Série B, Textos Básicos de Saúde, Série ODM Saúde Brasil, v.4).

Ministério da Saúde. Atenção humanizada ao recém-nascido de baixo peso: método canguru. 2.ed. Brasilia: MS, 2011.

BRAZELTON, T.B. O desenvolvimento do apego. Porto Alegre: Artes Médicas, 1988.

CANAULT, N. Comment le désir de naître vient au foetus. Paris: Desclée de Brouwer, 2001.

CRAWLEY, M.S. Development of a tool for the measurement of maternal attachment during pregnancy. Nurs. Res., v.30, n.5, p.281-4, 1981.

ESPINOSA, B. Ética. São Paulo: Abril Cultural, 1973.

FEIJÓ, M.C. Validação brasileira da "maternal-fetal attachment scale". Arq. Bras. Psicol., v.51, n.4, p.52-62,1999.

GOLSE, B. Le developpement affectif et intellectuel de l' enfant. Paris: Masson, 2008.

GOMES, M.; PINHEIRO, R. Acolhimento e vínculo: práticas de integralidade na gestão do cuidado em saúde em grandes centros urbanos. Interface (Botucatu), v.9, n.17, p.287-301, 2005.

GROSSMANN, K.; GROSSMANN, K.; WATERS, E. Apego: da infância à idade adulta - os principais estudos longitudinais. São Paulo: Roca, 2008.

GUIMARÃES, M.B.L. Intuição, pensamento e ação na clínica. Interface (Botucatu), v.9, n.17, p.317-32, 2005.

KLAUS, M.; KENNELL, J.H. Pais/bebê: a formação do apego. Porto Alegre: Artes Médicas, 1993.

LEBOYER, F. Shantala: uma arte tradicional massagem para bebês. São Paulo: Ground, 1986.

LUZ, M. Natural, racional, social: razão médica e racionalidade científica moderna. 2.ed. São Paulo: Hucitec, 2004.

MALDONADO, M.; CANELLA, P. Recurso de relacionamento para profissionais de saúde. Rio de Janeiro: Reichmann \& Afonso, 2003.

MAZET, P.; STOLERN, S. Manual de psicopatologia do recém-nascido. Porto Alegre: Artes Médicas, 1990.

MENDES, C. (Coord.). Sumário da pesquisa avaliativa da implantação da estratégia brasileirinhas e brasileirinhos saudáveis. Rio de Janeiro: Fiocruz, 2012.

MONTAGU, A. A pele e o tocar. São Paulo: Summus, 1971.

MOREIRA, M.; BRAGA, N.; MORSCH, D. Quando a vida começa diferente. Rio de Janeiro: Fiocruz, 2003.

MOURA, M.M. São muitos os remédios para os males dessa vida: análise de recursos terapêuticos a partir da doença crônica da infância. 2001. Tese (Doutorado) - Instituto de Medicina Social, Universidade do Estado do Rio de Janeiro, Rio de Janeiro. 2001.

MOURA, M.M.; CARNEIRO, S.V.M. Psicologia médica em maternidade pública de alto risco. In: LADVOCAT, C. (Org.). Psicologia: campo de atuação, teoria e prática. Rio de Janeiro: Booklink, 2010. p.302-8.

RIVIÈRE, P. O processo grupal. São Paulo: Martins Fontes, 1988. 
SCHRAIBER, L.B. Medicina tecnológica e prática profissional contemporânea: novos desafios, outros dilemas. 1997. Tese (Livre-docência) - Faculdade de Medicina, Universidade de São Paulo, São Paulo. 1997.

SOLIS-PONTON, L. (Org.). Ser pai, ser mãe, parentalidade: um desafio para o terceiro milênio. São Paulo: Casa do Psicólogo, 2004

SPINK, M.J. (Org.). Práticas discursivas e produção de sentidos no cotidiano: aproxi-ma-ções teóricas e metodológicas. São Paulo: Cortez, 1999.

STERN, D. A constelação da maternidade: o panorama da psicoterapia pais/bebê. Porto Alegre: Artes Médicas, 1981.

TAYLOR, A. et al. A new mother-to-infant bonding scale: links with early maternal mood. Arch. Wom. Ment. Health, v.8, n.1, p.45-51, 2005.

VELDMAN, F. Haptonomie: science de I'affectivité. Paris: Puf Ed., 1989.

WINNICOTT, D.W. Preocupação materna primária. In: (Org.). Textos selecionados: da pediatria à psicanálise. Rio de Janeiro: Francisco Alves, 1978. p.491-8.

MOURA, M. M. D.; GUIMARÃES, M. B. L.; LUZ, M. Tocar: atención al vínculo en al ambiente hospitalario. Interface (Botucatu), v.17, n.45, p.393-404, abr./jun. 2013.

Se investigaron los vínculos entre profesionales de la salud y pacientes en hospital maternal-infantil terciario y público, especializado en embarazo de alto riesgo fetal y en enfermedades de alta complejidad en la infancia y en la adolescencia, con el objetivo de verificar si las intervenciones que son "afectivas" (madres/bebés) podrían minimizar el estrés del ambiente de hospital e interferir positivamente en el proceso terapéutico. Nos referimos a las acciones que contribuyen con los vínculos entre el profesional de salud, paciente y bebé, que incluyen el cuidado profesional técnico y afectivo, el confort ambiental, los espacios para expresión de los sentimientos y comunicación. La investigación, de naturaleza empírico-operativa, utilizó metodología cualitativa (observación participante y análisis de discurso), teniendo como sujetos a madres, familiares y profesionales. Los resultados indican la importancia de la acogida y del vínculo entre profesionales de la salud y mujeres embarazadas que viven un embarazo de alto riesgo fetal en el ambiente de hospital investigado, pudiendo favorecer la construcción del vínculo posible entre padres y bebés en situaciones adversas.

Palabras clave: Apego a objetos. Tacto terapéutico. Relaciones médico-paciente. Atención perinatal. 